\title{
Relationship Between Organizational Learning and Employees' Empowerment: A Case Study Among Medical Sciences Staff
}

\author{
Ramin Ravangard ${ }^{1}$; Zahra Sajjadnia ${ }^{2}$; Marzie Farmani ${ }^{3}$; Mohammadkarim Bahadori ${ }^{4,}$ \\ ${ }^{1}$ Health Human Resource Research Center, School of Management and Medical Information Sciences, Shiraz University of Medical Sciences, Shiraz, IR Iran \\ ${ }_{3}^{2}$ Department of Statistics, Science College, Shiraz University, Shiraz, IR Iran \\ ${ }^{3}$ Student Research Committee, School of Management and Medical Information Sciences, Shiraz University of Medical Sciences, Shiraz, IR Iran \\ ${ }^{4}$ Student Research Committee, School of Management and Medical Information Sciences, Shiraz Univ \\ *Corresponding author: Mohammad Karim Bahadori, Health Management Research Center, Baqiyatallah University of Medical Sciences, Tehran, IR Iran. Tel: +98-2182482416, Fax: \\ +98-2188057022, E-mail: bahadorihealth@gmail.com
}

Received: October 31, 2013; Revised: December 12, 2013; Accepted: December 21, 2013

\begin{abstract}
Background: Universities, like any other organization, are working in a variable and dynamic environment. In order to empower these organizations to deal with constant change, they should focus on organizational learning.

Objectives: This research aimed to study the relationship between organizational learning and employees' empowerment among the headquarters staff of Shiraz University of Medical Sciences in 2013.

Patients and Methods: This was an applied, cross-sectional, and analytical-descriptive study. A sample of 100 headquarters staff of Shiraz University of Medical Sciences were selected using stratified sampling proportional to size, and simple random sampling methods. The required data were collected using two questionnaires. Collected data were analyzed by SPSS 18.0 and statistical tests including; ANOVA, independent-sample t-test as well as Pearson's correlation coefficient, and multiple linear regression (stepwise method). In all tests, P value $<0.05$ was considered statistically significant.

Results: The results showed that the studied employees' empowerment and organizational learning were moderate. In addition, the results of multiple linear regression indicated that only participation $(\mathrm{P}<0.001)$ and competence $(\mathrm{P}=0.001)$ had a positive and significant association with organizational learning.

Conclusions: The studied university could promote employees' empowerment and organizational learning using strategies including job enrichment, providing opportunities for innovation and creativity for their employees, giving rewards to individuals and team learning.
\end{abstract}

Keywords: Organizational Learning; Empowerment; Headquarters Staff

\section{Background}

Globalization has resulted in drastic changes in the environment, competition, and dynamic customer preferences, and this has forced organizations to adapt themselves to these issues in order to survive and succeed. These changes have occurred not only in the external environment, such as in products, services, and technologies, but also in the internal environment, like the way people think, their visions, values, and goals (1). In order to be empowered to deal with these changes, organizations should focus on organizational learning. In fact, a successful organization learns faster and adapts more quickly than its competitors. This is why attention to concepts of organizational learning has grown and been emphasized more strongly in recent years (2-4). Organizational learning has increasingly attracted attention in organizations that focus on increasing competi- tive advantages, innovation, and effectiveness. Organizational learning is a process that leads to employees' learning, and it includes specific organizational behavior observed in the learning organizations $(5,6)$. Fiol et al. and Dodgson have described organizational learning as a way of consolidating and stabilizing the organization, completing and organizing current knowledge about organizational activities and culture, as well as improving the process of activities through better knowledge and understanding $(7,8)$. Because of its importance, this concept has been classified from different views. One of the most well-known and comprehensive ones is Neefe's perspective in which organizational learning consists of seven dimensions, including shared vision, organizational culture, team learning, system thinking, participative leadership, personal mastery and sharing knowledge (9). Paying attention to organizational learning, particularly in higher education systems, is one of the most impor-

Implication for health policy/practice/research/medical education:

Given the positive and significant relationship between employees' empowerment and organizational learning, universities can achieve their goals and deal with environmental changes through relying on the factors that promote the empowerment of employees as well as providing opportunities for organizational learning.

Copyright (c) 2014, Health Promotion Research Center. This is an open-access article distributed under the terms of the Creative Commons Attribution License, which permits unrestricted use, distribution, and reproduction in any medium, provided the original work is properly cited. 
tant aspects of sustainable development. This is because universities are the most important elements of the teaching-learning process in society today $(10,11)$. Therefore, organizational learning is the main way to make knowledge work and improve organizational efficiency, particularly in the education system. Achieving organizational learning requires careful and constant attention to the empowerment of human resources at all organizational levels. Employees are the most important asset of an organization; hence, empowering them and creating motivated and empowered staff will allow managers to act quickly and appropriately in a changing and dynamic environment and provide competitive advantages for their organizations $(12,13)$.

Organizational empowerment means to empower employees; in other words, to help them to strengthen their self-confidence, overcome their sense of powerlessness and helplessness, and motivate them to perform activities. In empowerment, the employees will be given greater autonomy, self-determination, freedom and responsibility for making decisions (14). In fact, this concept can be seen as a set of motivational techniques that seek to increase the level of employees' participation in order to improve their performance. The main feature of employees' empowerment is to align individual and organizational goals (15). Psychological empowerment of employees is a new approach in intrinsic motivation that means setting the inner power and strength of individuals free and creating opportunities for developing the talents, abilities, and competence of the staff. It includes employees' perceptions of their role in the job and organization. Proponents of empowerment have considered it to be the foundation for continuous improvement by which employees feel valued and it also gives them a sense of self-worth (16).

Thomas and Velthouse defined empowerment as intrinsic job motivation that manifests in four cognitions reflecting an individuals' orientation to their work role, including; meaning, competence, self-determination, and impact (17-19). Empowerment is one of the important characteristics of learning organizations (1) and it can improve employees' performance (20-22), job satisfaction $(23,24)$, intrinsic motivation, and productivity (25). Therefore, the study of the association between these two important concepts should be considered as a priority more than ever. There are several studies concerning the relationship between organizational learning and employees' empowerment in different sectors including the health, industry. The results of Allahyari et al. (12), Darvish et al. (26) and Safari et al. (27) studies have shown a close and significant relationship between these two factors. In a study, the results showed that empowerment was essential for optimal job performance (28). However, there has not been any similar study on the headquarters staff of Universities of Medical Sciences in Iran and therefore, investigating this relationship in the health sector can be considered as new research.

\section{Objectives}

The present research aimed to study the relationship between organizational learning and employees' empowerment among the headquarters staff of Shiraz University of Medical Sciences in 2013 in order to provide opportunities for turning this university into a learning organization through empowering its headquarters staff.

\section{Patients and Methods}

This was an applied, cross-sectional, and analyticaldescriptive study conducted in 2013. The study population was all headquarters staff of Shiraz University of Medical Sciences working in six deputy departments and the university administration office $(n=1852)$. A sample of 100 employees was determined using the findings of previous studies, the results of the pilot study and the following formula, assuming $\alpha=0.05, \mathrm{r}=0.28$ and $\beta=$ 0.20 . This sample was selected using stratified sampling proportional to size and simple random sampling methods using random numbers table (Equation 1).

Equation 1. $\quad n=\left(\frac{Z_{1-\frac{\alpha}{2}+Z_{1-\beta}}}{\frac{1}{2} \ln \frac{1+r}{1-r}}\right)^{2}+3=98$

The required data were collected using two questionnaires. Employees' empowerment was measured using the modified Persian version of the empowerment questionnaire developed by Spreitzer (17) and modified by Allahyari et al. (12). This questionnaire consisted of 19 items measuring five dimensions of employees' empowerment, including; meaning (three items), competence (four items), self-determination (three items), impact (three items), and participation (six items). The inter-item consistency score $(\alpha=0.90)$ of the test was found to be adequate in Allahyari et al. study (12). Organizational learning dimensions were assessed using the modified Persianversion of a questionnaire developed by Neefe (9), modified by Allahyari et al. (12). This questionnaire consisted of 21 items assessing seven dimensions of organizational learning including shared vision (three items), organizational culture (three items), team learning (three items), strategy (three items), participative leadership (three items), personal mastery (three items), and organizational structure (three items). The inter-item consistency score $(\alpha=$ 0.86 ) of the test was also been found to be adequate in Allahyari et al. study (12).

The validity of the Persian version of the questionnaires was confirmed by Allahyari et al. (12). Five-point Likert scales were used to measure employments' empowerment and organizational learning, whereby one referred to strong disagreement and five as strong agreement. In addition, respondents were asked about their demographic profiles, such as gender, age, educa- 
tion level, job experience, and service department. For each studied variable the mean of more than 3.5 (70\% of the maximum possible mean) was considered as desirable, the mean of 2 - 3.5 (between $70 \%$ - 40\% of the maximum possible mean) as moderate, and the mean of less than 2 (less than $40 \%$ of the maximum possible mean) as an undesirable improvement state. It should be noted that the maximum possible mean was five. Informed consent was obtained from all employees participating in this study. SPSS 18.0 software (SPSS, Chicago, Illinois, USA) was employed to analyze the data. The statistical tests, including ANOVA, Independent-samples t-test, Pearson's correlation coefficient, and multiple linear regressions (stepwise method) were used to analyze the collected data. In all tests, P value $<0.05$ was considered statistically significant.

Table 1. Basic Characteristics of the Studied Employees

\begin{tabular}{|c|c|}
\hline Variables & Results, No. (\%) \\
\hline \multicolumn{2}{|l|}{ Age, $y$} \\
\hline$<34$ & $48(48)$ \\
\hline $34-44$ & $41(41)$ \\
\hline$>44$ & $11(11)$ \\
\hline \multicolumn{2}{|l|}{ Education level } \\
\hline Diploma & $13(13)$ \\
\hline Associate degree & $17(17)$ \\
\hline Bachelor's degree & $48(48)$ \\
\hline Master's and higher degrees & $22(22)$ \\
\hline \multicolumn{2}{|l|}{ Job experience, $y$} \\
\hline$<10$ & $57(57)$ \\
\hline $10-20$ & $31(31)$ \\
\hline$>20$ & $12(12)$ \\
\hline \multicolumn{2}{|l|}{ Gender } \\
\hline Male & $44(44)$ \\
\hline Female & $56(56)$ \\
\hline \multicolumn{2}{|l|}{ Employment status } \\
\hline Contractual employees & $56(56)$ \\
\hline Official and formal employees & $44(44)$ \\
\hline \multicolumn{2}{|l|}{ Service department } \\
\hline $\begin{array}{l}\text { Resources and management develop- } \\
\text { ment deputy department }\end{array}$ & $28(28)$ \\
\hline $\begin{array}{l}\text { Food and drug administration deputy de- } \\
\text { partment and treatment deputy department }\end{array}$ & $17(17)$ \\
\hline Health deputy department & $8(8)$ \\
\hline $\begin{array}{l}\text { Research and technology deputy depart- } \\
\text { ment }\end{array}$ & $10(10)$ \\
\hline Education deputy department & $4(4)$ \\
\hline $\begin{array}{l}\text { Cultural and student affairs deputy } \\
\text { department }\end{array}$ & $19(19)$ \\
\hline University administration office & $14(14)$ \\
\hline
\end{tabular}

\section{Results}

The results showed that the majority of the participants were female (56\%) and their proportion in different study groups were as follows: $48 \%$ were younger than 34 years old, 56\% were employed contractually, 28\% worked in the Resources and Management Development Deputy Department, $48 \%$ had a bachelor's degree and 57\% had less than ten years job experience (Table 1).

Furthermore, the mean of the studied employees' empowerment was $3.24 \pm 0.65$ which showed moderate improvement. Among its dimensions, meaning and participation had the highest (3.42 \pm 0.69$)$, and the lowest $(3.09 \pm 0.76)$ means, respectively, which meant moderate improvement. Moreover, the mean of organizational learning was $3.03 \pm 0.62$ which indicates moderate improvement. Among its dimensions, organizational structure and participative leadership had the highest (3.20 $\pm 0.85)$ and the lowest $(2.80 \pm 0.74)$ means, respectively, which also showed moderate improvement (Table 2). The results showed that employees' empowerment and organizational learning did not have any significant relationships with studied employees' basic characteristics, including gender, age, education level, job experience and service department $(\mathrm{P}>0.05)$. In addition, the results of Pearson's correlation coefficient showed that organizational learning and its dimensions had positive and significant correlations with employees' empowerment and its dimensions $(\mathrm{P}<0.05)$ (Table 3$)$.

Table 2. Dimensions of Employees' Empowerment and Organizational Learning ${ }^{\text {a }}$

\begin{tabular}{lc}
\hline Dimensions of Employees' Empowerment & Results \\
\hline Meaning & $3.42 \pm 0.69$ \\
Competence & $3.22 \pm 0.79$ \\
Self-determination & $3.13 \pm 0.85$ \\
Impact & $3.21 \pm 0.80$ \\
\hline Participation & $3.09 \pm 0.76$ \\
Empowerment (total) & $3.24 \pm 0.65$ \\
\hline Shared vision & $3.06 \pm 0.74$ \\
Organizational culture & $3.12 \pm 0.76$ \\
\hline Team learning & $3.03 \pm 0.77$ \\
Strategy & $3.08 \pm 0.30$ \\
\hline Participative leadership & $2.80 \pm 0.74$ \\
\hline Personal mastery & $2.90 \pm 0.75$ \\
\hline Organizational structure & $3.20 \pm 0.85$ \\
\hline Organizational learning (total) & $3.03 \pm 0.62$ \\
\hline a Data are presented in Mean $\pm S D$. & \\
\hline
\end{tabular}


Ravangard Ret al.

\begin{tabular}{|c|c|c|c|c|c|c|}
\hline Dimensions & Meaning & Competence & Self-Determination & Impact & Participation & Empowerment (Total) \\
\hline \multicolumn{7}{|l|}{ Shared vision } \\
\hline $\mathrm{r}$ & 0.298 & 0.509 & 0.339 & 0.474 & 0.520 & 0.535 \\
\hline$P$ & 0.003 & $<0.001$ & 0.001 & $<0.001$ & $<0.001$ & $<0.001$ \\
\hline \multicolumn{7}{|c|}{ Organizational culture } \\
\hline $\mathrm{r}$ & 0.384 & 0.399 & 0.361 & 0.423 & 0.509 & 0.512 \\
\hline $\mathrm{P}$ & $<0.001$ & $<0.001$ & $<0.001$ & $<0.001$ & $<0.001$ & $<0.001$ \\
\hline \multicolumn{7}{|c|}{ Team learning } \\
\hline $\mathrm{r}$ & 0.313 & 0.481 & 0.440 & 0.449 & 0.429 & 0.513 \\
\hline $\mathrm{P}$ & 0.002 & $<0.001$ & $<0.001$ & $<0.001$ & $<0.001$ & $<0.001$ \\
\hline \multicolumn{7}{|c|}{ Personal mastery } \\
\hline $\mathrm{r}$ & 0.292 & 0.481 & 0.443 & 0.478 & 0.609 & 0.582 \\
\hline $\mathrm{P}$ & 0.003 & $<0.001$ & $<0.001$ & $<0.001$ & $<0.001$ & $<0.001$ \\
\hline
\end{tabular}

\begin{tabular}{lccccc}
\hline \multicolumn{1}{l}{ Table 4. Organizational Learning-Associated Dimensions of Employees' Empowerment Using Multiple Linear Regression } \\
\hline Factors & $\mathbf{B}$ & SE & Beta & t & P Value \\
\hline Constant & 21.955 & 4.454 & - & 4.930 & $<0.001$ \\
Participation & 1.350 & 0.258 & 0.469 & 5.225 & $<0.001$ \\
Competence & 1.294 & 0.373 & 0.312 & 3.474 & 0.001 \\
\hline
\end{tabular}

Finally, the results of multiple linear regression showed that only participation $(\mathrm{P}<0.001)$ and competence $(\mathrm{P}=$ 0.001 ) had a positive and significant correlation with organizational learning (Table 4 ) which explained $48.9 \%$ $\left(R^{2}=0.489\right)$ of the variance in organizational learning, whereas $51.1 \%$ of the variance was unexplained. The identified equation explaining this relationship was:

$\mathrm{Y}=21.955+1.3350 \mathrm{X}_{1}+1.294 \mathrm{X}_{2}$

Where $\mathrm{Y}=$ organizational learning, $\mathrm{X}_{1}=$ participation and $\mathrm{X}_{2}=$ competence.

\section{Discussion}

Nowadays, organizations need to engage in continuous learning because of the rapid growth of technology and development in a competitive environment. In other words, today's organizations are forced not only to learn and adapt themselves to new knowledge, but also to have the ability to learn and use past knowledge $(29,30)$. The results of the present study showed that there were positive and significant correlations between the dimensions of employees' empowerment and organizational learning among the headquarters staff of Shiraz University of Medical Sciences. It also showed that an increase in employees' empowerment and its dimensions could increase organizational learning. Accordingly, organizations need creative, innovative and empowered employees to be able to adapt themselves to an uncertain environment and ongoing, fast, and complex changes and in return, organizations should provide opportunities for continuous learning for their staff. The results of studies by Ozaralli (31), Bowen et al. (32), Khanalizadeh et al. (3), Allahyari et al. (12), Safari et al. (27) and Darvish et al. (26) confirmed the results of the present study. According to our results, the employees' empowerment and organizational learning were moderate. In universities, there are good opportunities for moving towards organizational learning. However, some factors, including bureaucracy and formal structures, traditional hierarchy, using an authoritarian management style, managers' fear of losing power, control and authority, and the inability of staff to accept responsibility and make good decisions may hinder the empowerment of employees and the move towards organizational learning. These can be overcome by creating self-managed teams rather than using traditional hierarchies, delegating the authority of decisionmaking to employees, developing an organizational culture and supporting a learning environment.

Furthermore, the results of multiple linear regression showed that only participation and competence had positive effects on organizational learning. To increase employees' participation, decision-making authority should be delegated to them. Active participation and involvement of employees in decision-making is one of the most effective mechanisms of empowerment that can lead to an increase in employees' motivation, job satisfaction, and ultimately their empowerment. The study results of Allahyari et al. (12) are similar to the present study results. However, Safari et al. (27) in their study concluded that among the factors of psychological empowerment, competence, selfdetermination, impact, and meaning had the greatest ability to predict the organizational learning, respectively. 
In addition, competence in the study by Hashmi et al. (33) and meaning in the study by Khanalizadeh et al. (3) had the greatest impacts on organizational learning. Therefore, the results of these three studies are inconsistent with the current study results.

On the other hand, competence is like an umbrella that encompasses everything which has an impact on job performance, either directly or indirectly. In other words, competence shows a picture of a developed and mature person who has developed preparation abilities and capabilities required for doing a job (34). Competence means that individuals are skilled enough to do their work (35). In order to increase employees' competence, sufficient opportunities for innovation and creativity should be provided for all employees. They should do an entire job instead of just a small component of the work. Performance-based payment can encourage qualified and capable employees to develop and promote their competencies. Furthermore, providing applied and ongoing training can extend the competence of employees. In the current study, there were no significant associations between employees' empowerment, organizational learning, and the basic characteristics of studied employees, while the results indicated a weak effect of demographic variables on employees' empowerment and organizational learning. However, in a study by Abbasi Moghadam et al. (36) they concluded that sex and employment status had a significant association with two dimensions of organizational learning, namely, open space and experimentation, and systematic view. In general, the reasons for the differences observed between the present study results and the results of other studies previously mentioned may be due to differences in the type of samples and target populations, sample sizes, and the different dimensions assessed in these studies. The limitation of the present study was its cross-sectional design, as determining causal relationships in a cross-sectional study are difficult. Therefore, it is recommended that longitudinal studies are conducted to determine the causal relationship between employees' empowerment and organizational learning.

In conclusion, the results of this study showed that there were positive and significant correlations between the dimensions of employees' empowerment and organizational learning among the headquarters staff of Shiraz University of Medical Sciences. Moreover, the results of multiple linear regression showed that among the employees' empowerment dimensions, only participation and competence had a positive and significant association with organizational learning. Universities as important factors in economic, technological, political, industrial growth and development, like any other organization, should move towards organizational learning and become a learning organization in order to adapt to ongoing environmental changes. Given the positive and significant association between employees' empow- erment and organizational learning, universities can achieve their goals and deal with environmental changes through relying on factors that promote the empowerment of employees, as well as providing opportunities for organizational learning. Universities can encourage employees' empowerment and organizational learning by using certain strategies, including job enrichment, providing opportunities for innovation and creativity for employees, considering learning as a part of all organizational policies and business processes, providing effective teaching through employees' participation and relying on scientific methods, as well as giving rewards to individuals, and team learning.

\section{Acknowledgements}

The authors would like to express their gratitude to the studied headquarters staff for their cooperation with the researchers in collecting and analyzing data.

\section{Authors' Contribution}

Ramin Ravangard and Mohammad Karim Bahadori carried out the study design and manuscript draft. Zahra Sajjadnia performed the data analysis. Marzie Farmani performed the data collection. All authors read and approved the final manuscript.

\section{Financial Disclosure}

The authors declare that there are no conflicts of interest.

\section{Funding/Support}

This article was extracted from a research project supported financially by Shiraz University of Medical Sciences (grant No. 92-01-07-5746).

\section{References}

1. Bhaskar AU, Mishra B. Empowerment: a necessary attribute of a learning organization? Organ Markets Emerg Econ. 2010;1(2):48-70.

2. Behnami J. [Organizational learning]. Tadbir. 2005;161:19-25.

3. Khanalizadeh R, Kordnaiej A, Fani A, Moshabaki A. Study of the relationship between organizational learning and empowerment. J Change Manage. 2010;3:20-45.

4. Chakrabarty S, Roge JN. An evaluation of the Organizational Learning Survey. Psychol Rep. 2002;91(3 Pt 2):1255-67.

5. Ruiz Moreno J. [Organizational learning]. Rev Enferm. 2001;24(6):411-3.

6. Dowd SB. Organizational learning and the learning organization in health care. Hosp Mater Manage Q. 2000;21(3):1-3.

7. Fiol CM, Lyles MA. Organizational Learning. Acad ManagE Rev. 1985;10(4):803-13.

8. Dodgson M. Organizational learning: a review of some literatures. Organ Stud.1993;14(3):375-94.

9. Neefe DO. Comparing levels of organizational learning maturity of colleges and universities participating in traditional and nontraditional (Academic Quality Improvement project) accreditation process [M.S. Dissertation]. Menomonie: University of WisconsinStout; 2001.

10. Davodi A, Oshtori E. Relationship between spiritual leadership and organizational learning in secondary schools. Journal Educ 
Leadership Admin. 2011;5(3):31-49.

11. Kuokkanen L, Suominen T, Harkonen E, Kukkurainen ML, Doran D. Effects of organizational change on work-related empowerment, employee satisfaction, and motivation. Nurs Adm Q. 2009;33(2):116-24.

12. Allahyari R, shahbazi B, MirkamaliSM, Kharazi K. Survey of relationship between the psychological empowerment of employees with organizational learning. Procedia - Soc Behav Sci.2011;30:1549-54.

13. Lin CY. Empowerment in the service industry: an empirical study in Taiwan. J Psychol. 2002;136(5):533-54.

14. Gagné M, Deci EL. Self-determination theory and work motivation. Journal Organ Behav. 2005;26(4):331-62.

15. Jerez-Gómez P, Céspedes-Lorente J, Valle-Cabrera R. Organizational learning capability: a proposal of measurement. J Bus Res. 2005;58(6):715-25.

16. Demirc MK, Erbas A. Employee empowerment and its effect on organizational performance. 2nd International Symposium on Sustainable Development; June 8-9; Sarajevo. 2010.

17. Spreitzer GM. Psychological empowerment in the workplace: dimensions, measurement and validation. Acad Manag J. 1995;38(5):1442-65.

18. Spreitzer GM. Taking stock: A review of more than twenty years of research on empowerment at work. Hand Organ Behav. 2008:54-73.

19. Thomas KW, Velthouse B. Cognitive elements of empowerment: An "interpretive" model of intrinsic task motivation. Acad Manage Rev.1990;15(4):666-81.

20. Munjuri MG. The effect of human resource management practices in enhancing employee performance in catholic institutions of higher learning in kenya. Internat J Bus Admin. 2011;2(4):189.

21. Fernandez S, Moldogaziev T. Empowering public sector employees to improve performance: does it work? Am Rev Publ Admin. 2011;41(1):23-47.

22. Kok PC. A study of the impact of the empowerment on employee performance in the automative industry in Malaysia. Open University Malaysia; 2011

23. Fernandez S, MoldogazievT. Employee empowerment, employee attitudes, and performance: testing a causal model. Publ Admin Rev. 2013;73(3):490-506.
24. Humborstad SIW, Perry C. Employee empowerment, job satisfaction and organizational commitment: An in-depth empirical investigation. Chinese Manag Stud. 2011;5(3):325-44.

25. Yang SB, Choi SO. Employee empowerment and team performance: Autonomy, responsibility, information and creativity. Team Perf Manag. 2009;15(5/6):289-301.

26. Darvish H, Norozi M. Studying the relations of organizational learning with employee empowerment: a case study at tehran social security organization. Ann U Petrosani Econ. 2011;11(3).

27. Safari K, Haghighi AS, Rastegar A, Jamshidi A. The relationship between psychological empowerment and organizational learning. Procedia - Soc Behav Sci. 2011;30:1147-52.

28. Huddleston D. Empowerment of nursing staff for optimal job performance. J Nurs Adm. 1999;29(12):5-16.

29. Ngwenya-Scoburgh L. Organizational learning: An exploration of the influence of capabilities and factors. Ann Arbor, United States: Capella University; 2009.

30. Patnaik B, Beriha GS, Mahapatra SS, Singh N. Organizational learning in educational settings (technical): an Indian perspective. Learn Organ, The. 2013;20(2):153-72.

31. Özaralli N. Effects of transformational leadership on empowerment and team effectiveness. Leadership Organ Dev J. 2003;24(6):335-44.

32. Bowen GL, Rose RA, Ware WB. The reliability and validity of the school success profile learning organization measure. Eval Program Plann. 2006;29(1):97-104.

33. Hashmi MS, Naqvi IH. Psychological empowerment: a key to boost organizational commitment, evidence from banking sector of pakistan. Int J Hum Resour Stud. 2012;2(2).

34. Dianati M, Erfani M. Competencies, concepts and applications. Tadbir. 2009;206:14-9.

35. Draganidis F, Mentzas G. Competency based management: a review of systems and approaches. Inform Manag Comput Secur. 2006;14(1):51-64

36. Abbasi Moghadam MA, Bakhtiari M, Raadabadi M, Bahadori M. [Organizational learning and empowerment of nursing status; Tehran University of Medical Sciences]. Educ Strategies Med Sci. 2013;6(2):113-8. 